\title{
Haemato-bacteriological profile and antibiogram of suspected cases of early onset sepsis in very low birth weight neonates
}

\author{
Aditi Rawat ${ }^{1}$, *Omprakash Shital Shukla ${ }^{2}$ \\ Sri Lanka Journal of Child Health, 2019; 48(1): 59-64
}

\begin{abstract}
Introduction: The current Indian neonatal mortality rate is 28 per 1000 live births. Whilst the leading cause of mortality is prematurity and its complications, the second is neonatal sepsis.
\end{abstract}

Objectives: To describe spectrum of isolates in neonatal sepsis together with their antibiotic sensitivity pattern and significance of routine blood investigations for diagnosis of early onset septicaemia.

Method: A cross-sectional study was performed in 100 neonates with risk factors for septicaemia after obtaining informed consent. Routine blood investigations such as complete blood count and Creactive protein (CRP) were done on the first day of life. Specificity, sensitivity, positive predictive value and negative predictive value of total leucocyte count, absolute neutrophil count and CRP were calculated. Blood culture was done using Bactec Peds Plus/F culture as a gold standard to diagnose septicaemia. The study was approved by the Institutional Ethics Committee.

Results: Out of 100 neonates with suspected sepsis, 40 were found to have culture proven sepsis. CRP had the highest sensitivity $(45 \%)$ and negative predictive value $(71 \%)$, leucopenia had the highest positive predictive value $(72 \%)$ and neutropenia had the highest specificity $(91.7 \%)$. The common bacteria for early onset sepsis (EOS) were Klebsiella, Pseudomonas and methicillin resistant Staphylococcus Aureus (MRSA) contributing 17\% each to the bacteriological profile. All the gram negative bacteria in our study were sensitive to gentamicin and gram positive bacteria were sensitive to nitrofurantoin, tigecycline, tetracycline, vancomycin, teicoplanin, and linezolid.

${ }^{1}$ Third Year M.D. Resident, ${ }^{2}$ Additional Professor, Department of Paediatrics, $S S G$ Hospital and Medical College, Vadodara, Gujarat, India

*Correspondence: opshukla101@gmail.com

(Received on 04 May 2018: Accepted after revision on 29 June 2018)

The authors declare that there are no conflicts of interest

Personal funding was used for the project.

Open Access Article published under the Creative

Commons Attribution CC-BY (CC)
Conclusions: This study showed that leucopenia, neutropenia and CRP are good indicators of sepsis, when used in combination. A negative CRP can exclude sepsis as it has the highest negative predictive value. This study also showed that gram negative bacilli (Klebsiella and Pseudomonas) were the common organisms associated with early onset neonatal sepsis.

DOI: http://dx.doi.org/10.4038/sljch.v48i1.8654

(Keywords: Early onset sepsis, antibiotic sensitivity, bacteriological profile, haematological profile)

\section{Introduction}

The current Indian neonatal mortality rate is 28 per 1000 live births and in Gujarat it is 26 per 1000 live births ${ }^{1,2}$. Whilst the leading cause of mortality is prematurity and its complications, the second is neonatal sepsis ${ }^{2}$. Continuous monitoring blood culture systems (CMBCS), such as BACTEC, are presently the "gold standard" for the detection of bacteraemia and sepsis in the clinical setting 3 . CMBCS monitors carbon dioxide levels in the suspension and a significant rise in these levels indicates the presence of viable bacteria in the suspension and therefore in the blood ${ }^{3}$. Antibiotics have been used extensively in the management of sepsis and are sometimes used empirically without identifying the causative organisms or knowing the antibiotic sensitivity, leading to development of resistance. It is therefore necessary to know the bacteriological profile causing sepsis in our area and their sensitivity to antibiotics. This will promote rational use of antibiotics and reduce the development of antibiotic resistance. This study was undertaken to address the above stated issue.

\section{Objectives}

To describe spectrum of isolates in neonatal sepsis together with their antibiotic sensitivity pattern and significance of routine blood investigations for diagnosis of early onset septicaemia.

\section{Method}

This cross sectional single centre study was carried out over a period of 7 months in 2018 at level III neonatal intensive care unit (NICU) in S.S.G Hospital, and Medical College Baroda, Gujarat, India. Written informed consent was obtained from parents. 100 neonates, weighing 1499 g or less, 
admitted in NICU with one clinical feature and one risk factor for sepsis as mentioned in the inclusion criteria were included in the study.

\section{Clinical features}

- Feed intolerance

- Shock

- Lethargy

- Jaundice (predominantly direct bilirubinaemia)

- Respiratory distress

- Omphalitis.

- Abdominal distension

- Apnoea

- Convulsion

- Bleeding / petechiae / purpura

- Temperature instability- hypothermia /hyperthermia

Risk factors

- Chorioamnionitis

- Urinary tract infection in mother in the third trimester

- Maternal fever $>100^{\circ} \mathrm{F}$ during or within 2 weeks of delivery

- Multiple pricks ( $>3$ ) for blood sampling.

- Duration of labour exceeding 24 hours

- Foul smelling liquor

- Prolonged and difficult delivery with instrumentation

- Active resuscitation required in labour room

- History of top feed (any milk other than breast milk given to the neonate)

- $\quad$ Prolonged rupture of membranes $>24$ hours

- $\quad>3$ per vaginal examinations during labour

A detailed antenatal, natal and postnatal history followed by general and systemic examination of neonates was done in every case.

With proper aseptic precautions, $1 \mathrm{ml}$ of blood was taken for total leucocyte count (TLC), differential leucocyte count (DLC) and serum C-reactive protein (CRP) estimation. TLC and DLC were done using Horiba ABX Penta XLR cell counter machine. CRP was done by rapid latex agglutination slide test. Approximately $2 \mathrm{ml}$ of blood was drawn using a sterile syringe before administration of antibiotics and inoculated aseptically into a BACTEC PEDS PLUS/F culture vials. Antibiotic sensitivity test was done using standard disc diffusion technique. Sensitivity, specificity and positive predictive value of each sepsis marker was analysed. Treatment plan was modified according to blood culture and sensitivity to promote rational use of antibiotics. The standards which were used to consider the test result as positive were as follows:

1. TLC: Leucopenia $\left(<5,000 / \mathrm{mm}^{3}\right)$ or leucocytosis $\left(>20,000 / \mathrm{mm}^{3}\right)$.

2. Absolute neutrophil count (ANC): Neutrophilia or neutropenia (as per Mouzinhos chart) was divided into 3 categories:

\begin{tabular}{|c|l|c|}
\hline Neutropenia & \multicolumn{1}{|c|}{ Normal } & Neutrophilia \\
\hline$<1100 / \mathrm{mm}^{3}$ & $1100-$ & $>15,000 / \mathrm{mm}^{3}$ \\
& $15,000 / \mathrm{mm}^{3}$ & \\
\hline
\end{tabular}

3. CRP $>1 \mathrm{mg} / \mathrm{dl}$ was considered as positive.

4. BACTEC blood culture showing growth of an organism.

\section{Results}

During the study period, 100 preterm low birth weight neonates fulfilling the above inclusion criteria were recruited. Fifty two out of the 100 neonates were from intramural NICU and 48 were from extramural NICU. In the present study group maximum neonates belonged to the 31-34 week gestation age group. A male predominance with a female: male ratio of 1:1.4 was observed. In birth weight distribution, 19 neonates out of the 100 were extremely low birth weight (ELBW) neonates weighing $<1000 \mathrm{~g}$ and 81 neonates were in the weight range of 1000-1499g.

Routine haematological investigation profile was done as shown in Table 1 which depicts that probability of sepsis is more with leucopenia as compared to leucocytosis; neutropenia had better correlation with sepsis as compared to neutrophilia and positive CRP was more likely to be associated with sepsis as compared to negative CRP. 
Table 1: Correlation of haematological investigations with BACTEC culture positivity

\begin{tabular}{|l|c|c|c|c|}
\hline \multirow{2}{*}{ Variant } & \multicolumn{4}{c|}{ BACTEC culture } \\
\cline { 2 - 5 } & $\begin{array}{c}\text { Positive } \\
(\boldsymbol{n}=\mathbf{4 0})\end{array}$ & $\begin{array}{c}\text { Negative } \\
(\boldsymbol{n = 6 0 )}\end{array}$ & $\begin{array}{c}\text { Total } \\
(\boldsymbol{n}=\mathbf{1 0 0})\end{array}$ & $\begin{array}{c}\text { BACTEC } \\
\text { positivity }\end{array}$ \\
\hline Leucopenia $\left(<5000 / \mathrm{mm}^{3}\right)$ & 13 & 05 & 18 & $72 \%$ \\
\hline Leucocytosis $\left(>20,000 / \mathrm{mm}^{3}\right)$ & 02 & 04 & 06 & $33 \%$ \\
\hline Neutropenia $\left(<1100 / \mathrm{mm}^{3}\right)$ & 02 & 01 & 03 & $66 \%$ \\
\hline Neutrophilia $\left(>15,000 / \mathrm{mm}^{3}\right)$ & 02 & 02 & 04 & $50 \%$ \\
\hline C-reactive protein positive & 18 & 13 & 31 & $58 \%$ \\
\hline C-reactive protein negative & 22 & 47 & 69 & $32 \%$ \\
\hline
\end{tabular}

Using BACTEC blood culture as the gold standard for diagnosis of neonatal sepsis, diagnostic accuracy of haematological tests used as early indicators of sepsis was calculated as shown in
Table 2. CRP had the highest sensitivity (45\%) and negative predictive value $(71 \%)$, leucopenia had the highest positive predictive value $(72 \%)$ and neutropenia had the highest specificity $(91.7 \%)$.

Table 2: Comparison of sensitivity, specificity, positive predictive value, negative predictive value of various haematological parameters

\begin{tabular}{|l|c|c|c|c|}
\hline \multicolumn{1}{|c|}{ Test } & Sensitivity & Specificity & Positive predictive value & Negative predictive value \\
\hline $\begin{array}{l}\text { Leucopenia } \\
\left(\mathrm{TLC}<5000 / \mathrm{mm}^{3}\right)\end{array}$ & $32.5 \%$ & $91.7 \%$ & $72 \%$ & $62 \%$ \\
\hline $\begin{array}{l}\text { Neutropenia } \\
\left(\mathrm{ANC}<1100 / \mathrm{mm}^{3}\right)\end{array}$ & $05.0 \%$ & $98.3 \%$ & $66 \%$ & $60 \%$ \\
\hline CRP $(>1 \mathrm{mg} / \mathrm{dl})$ & $45.0 \%$ & $58.3 \%$ & $58 \%$ & $71 \%$ \\
\hline
\end{tabular}

TLC: Total leucocyte count, ANC: Absolute neutrophil count, CRP: C-reactive protein

BACTEC culture proven sepsis was seen in $40 \%$ cases and $60 \%$ were negative. Gram-negative septicaemia was predominant. The bacteriological profile seen in our study was Klebsiella (17.5\%), Pseudomonas (17.5\%), methicillin resistant Staphylococcus aureus (17.5\%), Staphylococcus aureus (12.5\%), Acinetobacter (12.5\%), Enterobacter (10\%), Enterococcus (7.5\%), Proteus (2.5\%), and Citrobacter (2.5\%). Antibiotic sensitivity was determined for gram negative and gram positive bacteria as depicted in Table 3 and 4 respectively.

Table 3: Antibiotic sensitivity patterns in gram-negative isolates (number \& \% showing sensitivity)

\begin{tabular}{|l|c|c|c|c|c|c|}
\hline & $\begin{array}{c}\text { Acinetobacter } \\
(\mathbf{n}=5)\end{array}$ & $\begin{array}{c}\text { Citrobacter } \\
(\mathbf{n}=\mathbf{1})\end{array}$ & $\begin{array}{c}\text { Enterobacter } \\
(\mathbf{n}=4)\end{array}$ & $\begin{array}{c}\text { Klebsiella } \\
(\mathbf{n}=7)\end{array}$ & $\begin{array}{c}\text { Proteus } \\
(\mathbf{n}=\mathbf{1})\end{array}$ & $\begin{array}{c}\text { Pseudomonas } \\
(\mathbf{n}=7)\end{array}$ \\
\hline & No. $(\%)$ & No. $(\%)$ & No. $(\%)$ & No. $(\%)$ & No. $(\%)$ & No. $(\%)$ \\
\hline Gentamycin & $01(20)$ & $01(100)$ & $03(75)$ & $03(43)$ & $01(100)$ & $05(71)$ \\
\hline Amikacin & $0(0)$ & $01(100)$ & $03(75)$ & $04(57)$ & $0(0)$ & $01(14)$ \\
\hline Ciprofloxacin & $02(40)$ & $01(100)$ & $03(75)$ & $03(43)$ & $0(0)$ & $06(85)$ \\
\hline Ceftriaxone & $01(20)$ & $01(100)$ & $02(50)$ & $01(14)$ & $0(0)$ & $0(0)$ \\
\hline Cefepime & $01(20)$ & $01(100)$ & $02(50)$ & $01(14$ & $0(0)$ & $0(0)$ \\
\hline Cefuroxime & $0(0)$ & $0(0)$ & $02(50)$ & $01(14)$ & $0(0)$ & $0(0)$ \\
\hline $\begin{array}{l}\text { Cefoperazone- } \\
\text { Sulbactam }\end{array}$ & $03(60)$ & $01(100)$ & $03(75)$ & $02(29)$ & $0(0)$ & $07(100)$ \\
\hline Ampicillin & $0(0)$ & $0(0)$ & $0(0)$ & $0(0)$ & $0(0)$ & $01(15)$ \\
\hline $\begin{array}{l}\text { Piperacillin- } \\
\text { Tazobactum }\end{array}$ & $01(20)$ & $01(100)$ & $03(75)$ & $02(29)$ & $0(0)$ & $0(0)$ \\
\hline Nitrofurantoin & $0(0)$ & $0(0)$ & $04(100)$ & $01(15)$ & $0(0)$ & $0(0)$ \\
\hline Tigecycline & $05(100)$ & $0(0)$ & $04(100)$ & $07(100)$ & $0(0)$ & $01(15)$ \\
\hline Meropenem & $0(0)$ & $0(0)$ & $03(75)$ & $01(14)$ & $0(0)$ & $0(0)$ \\
\hline $\begin{array}{l}\text { Trimethoprim- } \\
\text { Sulphamethoxazole }\end{array}$ & $03(60)$ & $0(0)$ & $03(75)$ & $04(57)$ & $01(100)$ & $01(14)$ \\
\hline Colistin & $04(80)$ & $0(0)$ & $02(50$ & $04(57)$ & $0(0)$ & $05(71)$ \\
\hline
\end{tabular}


Table 4: Antibiotic sensitivity patterns in gram positive isolates (number \& \% showing sensitivity)

\begin{tabular}{|l|c|c|c|}
\hline \multicolumn{1}{|c|}{ Antibiotic } & $\begin{array}{c}\text { Enterococcus (n=3) } \\
\text { No. (\%) }\end{array}$ & $\begin{array}{c}\text { MRSA (n=7) } \\
\text { No. (\%) }\end{array}$ & $\begin{array}{c}\text { Staphylococcus A (n=5) } \\
\text { No. (\%) }\end{array}$ \\
\hline Gentamycin & $0(0)$ & $04(57)$ & $03(60)$ \\
\hline Amikacin & $01(33)$ & $0(0)$ & $0(0)$ \\
\hline Ceftriaxone & $0(0$ & $0(0)$ & $05(100)$ \\
\hline Nitrofurantoin & $02(66)$ & $06(86)$ & $05(100)$ \\
\hline Tigecycline & $03(100)$ & $04(57)$ & $05(100)$ \\
\hline Trimethoprim-Sulphamethoxazole & $0(0)$ & $01(14)$ & $02(40)$ \\
\hline Levofloxacin & $01(33)$ & $0(0)$ & $01(20)$ \\
\hline Oxacillin & $0(0)$ & $0(0)$ & $01(20)$ \\
\hline Erythromycin & $01(33)$ & $0(0)$ & $01(20)$ \\
\hline Clindamycin & $0(0)$ & $04(57)$ & $01(20)$ \\
\hline Tetracycline & $03(100)$ & $06(86)$ & $05(100)$ \\
\hline Vancomycin & $02(66)$ & $07(100)$ & $03(60)$ \\
\hline Teicoplanin & $02(66)$ & $06(86)$ & $05(100)$ \\
\hline Daptomycin & $0(0)$ & $04(57)$ & $02(40)$ \\
\hline Linezolid & $03(100)$ & $05(71)$ & $02(40)$ \\
\hline
\end{tabular}

MRSA: methicillin resistant Staphylococcus aureus

\section{Discussion}

Neonatal sepsis is characterized by signs and symptoms of infection with or without bacteraemia in the first 4 weeks of life ${ }^{4}$. Early onset sepsis (EOS) occurs within 72 hours of life and is acquired before or during delivery or at the time of resuscitation in the labour room $^{5,6}$. The incidence of sepsis is higher among preterm infants and ranges from $15-23 \%$ per 1000 very low birth weight (VLBW) births ${ }^{7}$.

In our study neutropenia was associated with a higher probability of sepsis which is in accordance with a study by Lim $e t a l^{8}$. In a study by Shreshtha et $a l^{9}$, out of 37 neutropenic patients 22 had culture positive sepsis amounting to a culture positivity of $59 \%$ which was somewhat similar to our study. According to our study leucopenia was associated with a greater probability of sepsis. This is in accordance with a study by Kalpana et $a l^{10}$ which showed a $42 \%$ blood culture positivity rate with leucopenia and only a $29 \%$ culture positivity rate in cases with total leucocyte count (TLC) $>5000 / \mathrm{cu}$ $\mathrm{mm}$. This study showed a higher association of neutropenia with sepsis which was similar to observations in our study. The study by Roy et $a l^{11}$ also showed higher association of leucopenia with sepsis as compared to normal or high leucocyte counts.

In our study, CRP positivity has a positive correlation with culture positivity. A study by Lim et $a l^{8}$ showed elevated CRP in $84.2 \%$ BACTEC positive cases. The CRP positivity rate was higher as compared to our study because values of CRP change according to postnatal age. In a study by Kalpana et $a l^{10}$, out of 38 culture positive neonates, 30 had positive CRP amounting to $78 \%$ positivity. Similarly, a study done by Roy et $a l^{11}$ showed $28.5 \%$ culture positivity in CRP positive cases. Any rise in CRP in a newborn baby represents an endogenous synthesis as it crosses the placenta in very low amounts.

Leucopenia had a high specificity (91.7\%) and low sensitivity $(32.5 \%)$ which means that it is more accurate in excluding sepsis Its positive predictive value is high $(72 \%)$ which indicates that the probability of sepsis in subjects with leucopenia is high. Neutropenia had the highest specificity $(98.3 \%)$ which infers that the absence of neutropenia accurately excludes sepsis as compared to negative CRP and absence of leucopenia. It had the lowest sensitivity (5\%) and hence neutropenia cannot be used as a sole indicator to diagnose neonatal sepsis. CRP had the highest sensitivity (45\%) amongst all the tests, which means that in comparison to neutropenia and leucopenia CRP can more accurately identify those with sepsis. Specificity of CRP $(58.3 \%)$ is more than sensitivity. It had a high negative predictive value $(71 \%)$ and the lowest positive predictive value (58\%). A study by Kalpana et $\mathrm{al}^{10}$ concluded that leucopenia had a higher specificity $(66.6 \%)$ than sensitivity (47\%). This inference was similar to our study. CRP had a sensitivity of $88.2 \%$, a specificity of $87.8 \%$ and a positive predictive value of $88.8 \%$. In a study by Philip et $\mathrm{al}^{12}$, a white blood cell count $<5000 / \mathrm{mm}^{3}$ was found to have a specificity of $94 \%$ but a sensitivity of only $50 \%$, which was similar to 
our study. In the study by Ahmad et al 13, sensitivity, specificity, negative and positive predictive values for leucopoenia were $22 \%, 68 \%$, $29 \%$ and $59 \%$, respectively and for neutropenia they were $16 \%, 81 \%, 34 \%$ and $61 \%$ respectively.

The BACTEC blood culture positivity rate in our study was $40 \%$ predominantly due to gram negative organisms. Out of 40 culture positive cases $62.5 \%$ was contributed by gram negative bacteria and $37.5 \%$ by gram positive bacteria. The culture positivity in various studies conducted in term and preterm neonates was as follows: $33 \%$ by Sarangi K et al, $47 \%$ by Kayange N et al, $29.8 \%$ by Hoque $\mathrm{M}$ et al, $34 \%$ by Kalpana KL and $35.9 \%$ by Satyamurthi B et al with predominance of gram negative bacteria ${ }^{10,14-17}$.

In a large series of premature infants, EOS was associated with infection by $55 \%$ Gram-negative pathogens, 38\% Gram-positive pathogens, 5\% fungal pathogens and $2 \%$ other pathogens ${ }^{18}$. In this study the common organisms isolated were methicillin resistant Staphylococcus aureus (MRSA), Klebsiella and Pseudomonas. Single isolates of Proteus and Citrobacter were found in cases of maternal urinary tract infection. Common organisms for EOS seen in the study by Satyamurthi B et al ${ }^{16}$ were Klebsiella followed by Staphylococcus aureus. In a study by Lim WH et $a l^{8}$ E. coli $(40 \%)$ and Klebsiella $(20 \%)$ were the common organisms. In a study by Hoque $\mathrm{M}$, et $a l^{14}$ Acinetobacter (41.2\%) and Klebsiella pneumoniae $(23.5 \%)$ were the common organisms.

All the gram negative bacteria in our study were sensitive to gentamicin. Other antibiotics showing relatively higher sensitivity were ciprofloxacin, cefoperazone-sulbactum, cotrimoxazole, colistin and tigecycilne. All the gram negative isolates were resistant to cefuroxime. All the gram positive bacteria were sensitive to nitrofurantoin, tigecycline, tetracycline, vancomycin, teicoplanin and linezolid, while they were all resistant to gentamicin, levofloxacin, ciprofloxacin, penicillin and erythromycin. This study shows that bacteria are developing resistance against commonly used antibiotics and there is a dire need to use antibiotics rationally to prevent development of drug resistant strains.

An alarmingly high rate of MRSA was also observed for EOS. In view of the current sensitivity pattern empiric treatment for VLBW neonates should include a combination of antibiotics covering both gram positive and gram negative bacteria like cefoperazone-sulbactum with vancomycin.

\section{Conclusions}

This study showed that leucopenia, neutropenia and CRP are good indicators of sepsis, when used in combination. A negative CRP can exclude sepsis as it has the highest negative predictive value. This study also showed that gram negative bacilli (Klebsiella and Pseudomonas) were the common organisms associated with early onset neonatal sepsis.

\section{References}

1. SRS statistical report 2013. Available at http://niti.gov.in/content/neo-natalmortality-ratenmr-1000-live-births. Accessed on December 10, 2017.

2. Sanskar MJ, Neogi SB, Sharma J, Chauhan M, Shrivastava R, Prabhakar PR et al. State of newborn health in India. Journal of Perinatology 2016; 36(3):3-8. https://doi.org/10.1038/jp.2016.183 PMid: 27924104 PMCid: PMC5144119

3. Puttuswamy S, Lee B, Sengupta S. Novel Electrical Method for Early Detection of Viable Bacteria in Blood Cultures. Journal of Clinical Microbiology 2011; 49(6):2286-9.

https://doi.org/10.1128/JCM.00369-11

PMid: 21471337 PMCid: PMC3122763

4. Sudhir D, Ahmed R, Reddy L, Ramesh K. Profile of neonatal sepsis in a tertiary care hospital: A descriptive study. International Journal of Current Research and Academic Review 2014; 2(11):197202.

5. Singh M. Care of the newborn. 8th ed. Faridabad: CBS Publisher and distributors; 2017:283-297

6. Kleigman R, Nelson W. Nelson Textbook of Pediatrics. 1st Southeast Asian edition. Philadelphia: Elsevier Saunders; 2015:909-25

7. Cloherty J, Eichenwald E, Hansen A. Manual of Neonatal Care. 7th ed. Philadelphia: Wolters Kluwer; 2015. p 624-55.

8. Lim WH, Lien R, Huang Y-C, Chiang MC, Fu R-H, Chu S-M, et al. Prevalence and Pathogen Distribution of Neonatal Sepsis Among Very-Low-Birth-Weight Infants. Pediatric Neonatology 2012; 53(4):22834. 
https://doi.org/10.1016/j.pedneo.2012.06.0

03

PMid: 22964280

9. Shrestha L, Shrestha P. Mortality and Morbidity Pattern of Preterm Babies at a Tertiary Level Hospital in Nepal. Journal of Nepal Paediatric Society 2013; 33(3): 201-5.

https://doi.org/10.3126/jnps.v33i3.9200

10. Kalpana KL. Outcome of neonatal sepsis and statistical analysis of sepsis screening markers for early diagnosis. IOSR Journal of Dental and Medical Sciences 2016; 15(11):40-3.

11. Roy P, Kumar A, Faridi MMA, Kaur IR, Kashyap B. Clinico-bacteriological profile of neonates born with risk factors of septicaemia. Indian Journal of Neonatal Medicine and Research 2014; 2(1):1-6.

12. Philip AG, Hewitt JR. Early diagnosis of neonatal sepsis. Pediatrics 1980; 65:103641.

PMid: 7367117

13. Ahmad I, Ahmed A, Abrar SS, Lone M, Khanday MR, Bhat JI et al. Changing role of neonatal sepsis markers in the era of BacT/Alert: is there a need to devise a new septic screen? International Journal of Contemporary Pediatrics 2016; 3:10712.

https://doi.org/10.18203/23493291.ijcp201 60140

14. Hoque M, Ahmed A, Halder S, Khan M, Chowdhury M. Morbidities of preterm VLBW neonates and the bacteriological profile of sepsis cases. Pulse 2010; 4(1):59.
15. Sarangi K, Pattnaik D, Mishra S, Nayak M, Jena J. Bacteriological profile and antibiogram of blood culture isolates done by automated culture and sensitivity method in a neonatal intensive care unit in a tertiary care hospital in Odisha, India. Journal of Advances in Medicine and Medical Research 2015; 2: 387-92.

https://doi.org/10.18203/23493933.ijam20 151015

16. Sathyamurthi B, Leela KV, Narayanababu R, Padmanaban S, Sreedevi S, Sujatha et al. Clinical and bacteriological profile of neonatal sepsis in a tertiary care hospital. International Journal of Scientific Study 2016; 4(8):5760.

17. Kayange N, Kamugisha E, Mwizamholya DL, Jeremiah S, Mshana SE. Predictors of positive blood culture and deaths among neonates with suspected neonatal sepsis in a tertiary hospital, Mwanza- Tanzania. BMC Pediatrics 2010; 10(39):1-9. https://doi.org/10.1186/1471-2431-10-39

18. Simonsen KA, Anderson Berry L, Delair SF, Davies HD. Early-onset neonatal sepsis. Clinical Microbiology Reviews 2014; 27(1):21-47.

https://doi.org/10.1128/CMR.00031-13

PMid: 24396135 PMCid: PMC3910904 